\title{
Biodiesel as a Plasticizer of a SBR-Based Tire Tread Formulation
}

\author{
Franco Cataldo, ${ }^{1,2,3}$ Ornella Ursini, ${ }^{4}$ and Giancarlo Angelini ${ }^{4}$ \\ ${ }^{1}$ Dipartimento di Scienze Ecologiche e Biologiche, Università della Tuscia, Largo Università snc, 01100 Viterbo, Italy \\ ${ }^{2}$ Soc Lupi Chemical Research srl, Via Casilina 1626A, 00133 Rome, Italy \\ ${ }^{3}$ University of Rome Tor Vergata, Via della Ricerca Scientifica, 00133 Rome, Italy \\ ${ }^{4}$ Istituto di Metodologie Chimiche, CNR, Via Salaria Km 29,300, Monterotondo Stazione, 00016 Rome, Italy
}

Correspondence should be addressed to Franco Cataldo; franco.cataldo@fastwebnet.it

Received 25 January 2013; Accepted 17 February 2013

Academic Editors: T. R. Chantara, S.-H. Jafari, G.-H. Kim, B. Kiskan, and G. Lapienis

Copyright (C) 2013 Franco Cataldo et al. This is an open access article distributed under the Creative Commons Attribution License, which permits unrestricted use, distribution, and reproduction in any medium, provided the original work is properly cited.

\begin{abstract}
The solubility parameter of a series of methyl esters of fatty acids, the components of biodiesel, was calculated using the group incremental method proposed by Van Krevelen. The solubility parameter of biodiesel was compared with that of a series of rubbers like EPDM, butyl rubber, polyisoprene, polybutadiene, SBR (with different content of styrene), and nitrile rubber (with different content of acrylonitrile) showing that biodiesel is an effective solvent of all the above mentioned rubbers with the exclusion of nitrile rubber. Indeed, it was experimentally verified that polyisoprene, polybutadiene and SBR are easily soluble in biodiesel while polystyrene gives a cloudy solution. Considerations on the solubility parameter of the biodiesel and of a series of rubbers have led to the conclusion that biodiesel behaves essentially as an internal lubricant in a diene rubber matrix, the same situation occurs with the common aromatic mineral oil plasticizer known as T-RAE. The experimental evaluation of biodiesel as plasticizer in an SBRbased rubber compound in comparison to an aromatic mineral oil have led to the primary conclusion that biodiesel is reactive with the sulphur curing agent subtracting sulphur to the crosslinking polymer chains and leading to a vulcanizatewith lower moduli, tensile and hardness and higher elongations in comparison to a reference compound fully plasticized with an aromatic mineral oil. However, biodiesel seems a good low temperature plasticizer because the low elastic modulus observed is desired in a winter tire tread for a good grip on snow and ice. The present work is only an exploratory work, and the tire tread formulation with biodiesel was not optimized.
\end{abstract}

\section{Introduction}

Typical plasticizers of rubber compounds are aromatic, naphthenic or paraffinic oils. These plasticizers are obtained from the processing of petroleum fractions, and they have not an univocal chemical structure but are mixtures of complex molecules of relatively high molecular weight. For example, a plasticizer is defined aromatic because in its "average" molecule is made predominantly by aromatic hydrocarbons intended as benzenoid or polycyclic aromatic moieties. Such aromatic moieties may represent the "core" of the "average" plasticizer molecule, and such "core" is functionalized by alkyl and naphthenic substituents. The aliphatic side chains and the naphthenic moieties (intended, e.g., as a cyclopentane, cyclohexane, decalin rings attached to the aromatic "core") represent the minor component of the aromatic plasticizer molecule. Conversely, a naphthenic plasticizer is predominantly composed by cycloaliphatic rings of various types with some aromatic and aliphatic substituent. Thus, in this case the core of the molecule is represented by the cycloaliphatic moiety. Finally, the aliphatic plasticizer is essentially paraffinic in its nature, but its molecule is still composed also by a minor component of aromatic and naphthenic nature [1]. The molecular weight of an aromatic plasticizer is about 550 Dalton followed by the molecular weight of a naphthenic plasticizer which is reported at about 440 Dalton and the lightest "average" molecule is represented by the paraffinic plasticizer at about 350 Dalton [1]. The molecular geometry also affects the glass transition temperature $\left(T_{g}\right)$ of the plasticizers, and consequently, the $T_{g}$ of the aromatic plasticizer can be found at $-38^{\circ} \mathrm{C}$ while the naphthenic plasticizer $T_{g}=-72^{\circ} \mathrm{C}$ and the $T_{g}$ for the paraffinic plasticizer can be down to $-110^{\circ} \mathrm{C}[1]$. The solubility 
of the plasticizer in a given rubber matrix is extremely important for the final properties of a rubber vulcanizate [2]. In the present work, we will discuss the solubility of the just mentioned conventional plasticizers in a series of common rubbers used for tires and other rubber goods manufacture such as conveyor belts and shoe soles in terms of solubility parameter and the resulting effects in viscoelastic properties of the vulcanizate. Furthermore, we will introduce a new "green" plasticizer consisting in a mixture of methyl esters of fatty acids derived from rapeseed oil and commonly known as biodiesel, and we will test such a plasticizer in a standard rubber compound for a tire tread application.

Biodiesel is commonly obtained from the transesterification of rapeseed or canola oil with methanol [8-11]. Of course, other oils can be used such as palm oil, soybean oil, and other fats of vegetal or even animal origins and can be transesterified not only with methanol but also with higher aliphatic alcohols [12]. Biodiesel is produced as a vegetable fuel for diesel engines but because of its increasing availability and competitive price it could be used as a plasticizer and lubricant for rubber and plastics compounding with the advantage of using a raw material from renewable sources which is also environmentally compatible in terms of biodegradability. The idea is not completely new, since we can find traces of this application of fatty acids esters as plasticizer in the literature of the seventies of the last century [13], but the interest increased dramatically in more recent times as testified by patents $[14,15]$ and works in the open scientific literature [16-19]. Although vegetable oils have been occasionally used in the past at additives in plastics and rubbers, in this work, we are focusing our attention on the methyl esters of fatty acids. In the previous paragraphs, we have reported the low temperature behavior of the plasticizers derived from mineral oil. The low temperature properties of a plasticizer are of paramount importance also in the low temperature behavior of the compounds where a given plasticizer is used. Lower congealing point plasticizers give best low temperature flexibility to the rubber matrix where they are hosted. Concerning the biodiesel, the fatty acids methyl esters with highest unsaturation are those with the lowest melting point. For example, methyl linolenate (3 double bonds) has a melting point of $-57^{\circ} \mathrm{C}$ followed by methyl linoleate ( 2 double bonds) melting at $-35^{\circ} \mathrm{C}$ and by methyl oleate ( 1 double bond) with a melting point of $-19^{\circ} \mathrm{C}$. The fully saturated methyl stearate melts at $+40^{\circ} \mathrm{C}$.

It is worth mentioning here that castor oil is used in the formulation of butyl rubber compounds, epoxidized linseed oil is widely used in plastics and rubber as plasticizer and heat stabilizer, and vulcanized vegetable oils (known as factices) are used for long time in elastomers to ensure low temperature flexibility and low hardness [2].

\section{Experimental}

2.1. Materials Used. The biodiesel used in the present work was obtained from the transesterification with methanol of rapeseed oil and was characterized by a congealing point of $-15^{\circ} \mathrm{C}$ and by an iodine number of $115 \mathrm{~g} / 100 \mathrm{~g}$. It was synthesized in the Actinium srl laboratory. The aromatic mineral oil plasticizer was a commercially available plasticizer known as T-RAE (Treated Residual Aromatic Extract).

2.2. Mixing and Testing. The formulation where the two plasticizers were tested was a standard tire tread formulation composed by $137.5 \mathrm{phr}$ of oil extended solution styrenebutadiene copolymer (S-SBR) having $18 \%$ of bound styrene and $15 \%$ of vinyl groups. Carbon black N234 was used as filler ( $88 \mathrm{phr}$ ) and the free plasticizer added to the formulation (either T-RAE or biodiesel) was $18 \mathrm{phr}$. Other components are stearic acid: $1.5 \mathrm{phr}, \mathrm{ZnO} 3.5$ : phr, paraffin wax: 1 phr, antidegradant 6PPD (N-1,3-dimethylbutyl$\mathrm{N}$-phenyl-p-phenylenediamine): 1 phr, MBTS (mercaptobenzothiazole disulphide): $1 \mathrm{phr}$, TBBS (t-butyl benzothiazyl sulphenamide): $1 \mathrm{phr}$, and soluble sulphur: $2.7 \mathrm{phr}$. The compounds were prepared in two mixing stages. In the first mixing stage, all ingredients were added with the exception of sulphur, MBTS, and TBBS. In the second stage of mixing also the curatives were added. The vulcanization was conducted in a laboratory curing press at $160^{\circ} \mathrm{C}$ for 15 minutes.

Rheometer curves, Mooney viscosity, and Mooney scorch as well as the measurement of the tensile strength and the moduli were made according to standard tests procedures following ASTM or ISO standard practice.

The dynamic properties were measured on a mechanical spectrometer under temperature sweep conditions from $-30^{\circ} \mathrm{C}$ to $+80^{\circ} \mathrm{C}$ on a strip of rubber specimen under $1 \%$ strain and $80 \mathrm{~Hz}$.

2.3. Experimental Solubility Test. Polyisoprene (200 mg) was stirred with $24 \mathrm{~mL}$ of biodiesel in a glass vial with screw cap at $80^{\circ} \mathrm{C}$. The complete dissolution of polyisoprene was observed after $5 \mathrm{~h}$. The same experiment was repeated with a sample of $200 \mathrm{mg}$ of polybutadiene and $24 \mathrm{~mL}$ of biodiesel under identical conditions. The complete dissolution of polybutadiene was reached in $4 \mathrm{~h}$. Also $200 \mathrm{mg}$ of SBR (S1500 type) is soluble in biodiesel under the just described testing conditions. Finally, $75 \mathrm{mg}$ of polystyrene is also soluble in $24 \mathrm{~mL}$ of biodiesel under the reported testing conditions but the solution remains somewhat cloudy.

\section{Results and Discussion}

3.1. The Solubility Parameter. The solubility parameter has been defined by Brydson [2] as

$$
\delta=\left[\frac{\left(\Delta H_{\mathrm{vap}}-R T\right)}{V_{m}}\right]^{0.5} .
$$

The evaporation enthalpy $\Delta H_{\text {vap }}$ was taken as the parameter of the cohesion energy between molecules minus the thermal energy needed to separate them (RT) divided by the molar volume $V_{m}$. Equation (1) can be rewritten as

$$
\delta=\left[\frac{\left(E_{\mathrm{coh}}\right)}{V_{m}}\right]^{0.5} \text {. }
$$


The cohesive energy $E_{\text {coh }}$ of a substance in a condensed state is defined as the increase in internal energy $\Delta U$ per mole of substance if all the intermolecular forces are eliminated.

Hansen [6] has shown that the solubility parameter proposed by Hildebrand and Scott does not take into account the contribution of polar forces and hydrogen bonding; therefore, a more complex solubility parameter has been proposed:

$$
\delta^{2}=\delta_{d}^{2}+\delta_{p}^{2}+\delta_{h}^{2}
$$

derived from the contribution of three components of the cohesive energy:

$$
E_{\mathrm{coh}}=E_{d}+E_{p}+E_{h}
$$

respectively, due to the contribution of dispersion and polar forces plus a hydrogen bonding contribution.

It is possible to calculate the solubility parameter and the solubility parameter components of almost all molecules and polymers by a group contribution method [20, 21]. For this purpose, as explained by Van Krevelen [21], it is useful to introduce the molar attraction constant simply defined as

$$
\varphi=\left(E_{\mathrm{coh}} V_{m}\right)^{0.5} \text {. }
$$

A set of equations has been proposed by Van Krevelen [21] for the calculation of the solubility parameter components using the molar attraction by a group contribution methodology:

$$
\begin{gathered}
\delta_{d}=\frac{\left(\sum \varphi_{d}\right)}{V_{m}}, \\
\delta_{p}=\frac{\left(\sum \varphi_{p}^{2}\right)^{0.5}}{V_{m}}, \\
\delta_{h}=\left[\frac{\sum E_{h}}{V_{m}}\right]^{0.5} .
\end{gathered}
$$

The total solubility parameter can be calculated as follows:

$$
\delta_{t}=\left(\delta_{d}^{2}+\delta_{p}^{2}+\delta_{h}^{2}\right)^{0.5}
$$

It can be observed from (8) that the hydrogen bond parameter $\delta_{h}$ cannot be calculated from the molar attraction, but directly from the hydrogen bonding energy $E_{h}[21]$.

\subsection{The Solubility Parameter of Fatty Acid Glycerides and} Methyl Esters. In a previous work, Cataldo [3] has calculated the solubility parameter of a series of vegetable oils as triglycerides of fatty acids using the group increment method proposed by Van Krevelen [21] using (6)-(9). The calculation procedure involved as a first step the calculation of the solubility parameter of a single triglyceride of a given fatty acid, and then, knowing the fatty acids composition of a given oil, the following step was to proceed with the calculation of the solubility parameter of the vegetable oil considering the molar fraction of each fat in the vegetable oil. The details of the calculations are reported in [3]. Table 1 shows the calculated solubility parameters of several vegetable oils. The data are compared with some solubility parameter taken from the literature. The $\delta_{t}$ value calculated by Cataldo [3] for olive oil $16.9 \mathrm{MPa}^{1 / 2}$ is in good agreement with the value reported by Vaughan [4]. Instead, for linseed oil the $\delta_{t}$ value obtained by Cataldo [3] appears in line with all the other vegetable oils, that is, $16.4 \mathrm{MPa}^{1 / 2}$, and in this context, it appears surprisingly lower than the $\delta_{t}=14.8 \mathrm{MPa}^{1 / 2}$ found by Vaughan [4] for the same vegetable oil. Indeed, Cataldo has shown that $\delta_{t}$ for all the vegetable oils considered is comprised between 16.2 and $16.9 \mathrm{MPa}^{1 / 2}$, and hence, it appears anomalous the $\delta_{t}=18.0 \mathrm{MPa}^{1 / 2}$ reported in [5] for the brassica or rapeseed oil. The correct value of the solubility parameter for brassica oilseed should be $\delta_{t}=16.9 \mathrm{MPa}^{1 / 2}$. The solubility parameter of the methyl esters of erucic acid, oleic acid, linoleic acid, stearic acid, and palmitic acid was made using (6)-(9) and the tabulated values of $\varphi_{d}, \varphi_{p}$, and $E_{h}$ as reported by Van Krevelen [21]. The density values of the methyl esters were taken from the literature $[8,9,22]$. The resulting solubility parameters are reported in Table 1 . The $\delta_{t}$ values of the methyl esters considered as components of biodiesel are practically identical and comprised in the range between 16.6 and $16.7 \mathrm{MPa}^{1 / 2}$. Consequently, the solubility parameter of biodiesel is necessarily in this range, since the biodiesel is composed exclusively by a mixture of methyl esters of fatty acids. Other authors [7] have reported a slight higher value for the solubility parameter of biodiesel as shown in Table 1 .

3.3. The Solubility Parameter of Rubbers and Mineral Oil Plasticizers. In Table 2, the solubility parameters of a series of common rubbers are reported. Large part of the values were taken from [2]. In the case of the "styrene-butadiene copolymers, the solubility parameter was estimated according to the following:

$$
X_{\text {styrene }} \delta_{t \mathrm{PS}}+X_{\text {butadiene }} \delta_{t \mathrm{BR}}=\delta_{t \mathrm{SBR} \text { copolymer }},
$$

where $X_{\text {styrene }}$ and $X_{\text {butadiene }}$ are the weight fractions of these components in the copolymer and $\delta_{t \mathrm{PS}}$ and $\delta_{t \mathrm{BR}}$ are the solubility parameters of pure polystyrene and pure polybutadiene used in the copolymer. Similarly, for the nitrile rubber use was made of the analogous relationship:

$$
X_{\text {acrylonitrile }} \delta_{t \mathrm{ACN}}+X_{\text {butadiene }} \delta_{t \mathrm{BR}}=\delta_{t \text { Nitrile copolymer, }}
$$

where $X_{\text {acrylonitrile }}$ and $X_{\text {butadiene }}$ are the weight fractions of these components in the copolymer and $\delta_{t \mathrm{ACN}}$ and $\delta_{t \mathrm{BR}}$ are the solubility parameters of pure polystyrene and pure polybutadiene used in the copolymer.

In [2], the solubility parameters of an aromatic and paraffinic oil plasticizers are also reported, as shown in Table 2. However, the solubility parameters are too close, each other and do not reflect the real chemical and physical difference among the two oils. Therefore, we have recalculated the solubility parameter of these oils and also of naphthenic oil according to the following considerations.

(a) Paraffinic Oil. It is essentially made of linear and branched paraffin chains which represent about $70 \%$ of the total carbon 
TABLE 1: Solubility parameter of vegetable oils and methyl esters of fatty acids.

\begin{tabular}{lc}
\hline & $\delta_{t}$ in $\mathrm{MPa}^{1 / 2}$ \\
\hline Olive oil [3] & $\mathbf{1 6 . 9}$ \\
Olive oil [4] & 16.1 \\
Soybean oil [3] & $\mathbf{1 6 . 2}$ \\
Sunflower oil [3] & $\mathbf{1 6 . 7}$ \\
Peanut oil [3] & $\mathbf{1 6 . 1}$ \\
Linseed oil [3] & $\mathbf{1 6 . 4}$ \\
Linseed oil [4] & 14.8 \\
Brassica or rapeseed oil [3] & $\mathbf{1 6 . 9}$ \\
Brassica or rapeseed oil [5] & 18.0 \\
Glyceryl trioleate [3] & $\mathbf{1 6 . 9}$ \\
Glyceryl tristearate [3] & $\mathbf{1 7 . 7}$ \\
Castor oil [3] & $\mathbf{1 8 . 3}$ \\
Methyl erucate (this work) & 16.6 \\
Methyl oleate (this work) & 16.7 \\
Methyl oleate [4] & 16.4 \\
Methyl oleate [6] & 15.5 \\
Methyl linoleate (this work) & 16.6 \\
Methyl stearate (this work) & 16.7 \\
Methyl palmitate (this work) & 16.6 \\
Biodiesel (this work) & $16.65 \pm 0.05$ \\
Biodiesel [7] & $17.56 \pm 0.27$ \\
\hline
\end{tabular}

TABLE 2: Solubility parameter of rubbers and mineral oils plasticizers.

\begin{tabular}{lc}
\hline & $\delta_{t}$ in $\mathrm{MPa}^{1 / 2}$ \\
\hline EPDM and butyl rubber [2] & 16.1 \\
Polyisoprene and natural rubber [2] & 16.5 \\
Polybutadiene [2] & 17.1 \\
Styrene-butadiene copolymer 20\% styrene & 17.4 \\
(this work) & \\
Styrene-butadiene copolymer 40\% styrene & 17.7 \\
(this work) & 18.7 \\
Polystyrene [2] & 19.4 \\
Acrylonitrile-butadiene copolymer 20\% & \\
acrylonitrile (this work) & 20.6 \\
Acrylonitrile-butadiene copolymer 30\% & \\
acrylonitrile (this work) & 28.7 \\
Polyacrylonitrile & 16.4 \\
Aromatic oil plasticizer [2] & 15.3 \\
Paraffinic oil plasticizer [2] & $\mathbf{1 7 . 3}$ \\
Aromatic oil plasticizer (this work) & $\mathbf{1 5 . 7}$ \\
Naphthenic oil plasticizer (this work) & $\mathbf{1 4 . 2}$ \\
Paraffinic oil plasticizer (this work) &
\end{tabular}

atoms and which may be best represented by neopentane which has a solubility parameter of $12.8 \mathrm{MPa}^{1 / 2}$ [2]. The naphthenic part of the oil can be represented by the cyclohexane molecule which has a $\delta_{t}=16.8 \mathrm{MPa}^{1 / 2}$ [6], and the naphthenic molecules may represent $20 \%$ of the total carbon atoms. The aromatic carbon atoms are only $10 \%$ of the paraffinic oil and are represented by the benzene molecule with $\delta_{t}=18.5 \mathrm{MPa}^{1 / 2}$ [6]. Then, the solubility parameter calculation of the paraffinic oil is quite straightforward according to

$$
(0.7 \times 12.8)+(0.2 \times 16.8)+(0.1 \times 18.5)=14.2 \mathrm{MPa}^{1 / 2} .
$$

(b) Naphthenic Oil. It is essentially made a "core" of naphthenic rings which are well represented by cyclohexane whose solubility parameter is $16.8 \mathrm{MPa}^{1 / 2}$ [6], representing about $45 \%$ of the total carbon content. The paraffinic part of the molecule represents about $35 \%$ of the total carbon atoms which may be best represented by neopentane which has a solubility parameter of $12.8 \mathrm{MPa}^{1 / 2}$ [2]. The aromatic carbon atoms are about $20 \%$ of the naphthenic oil and are represented by the benzene molecule with $\delta_{t}=18.5 \mathrm{MPa}^{1 / 2}$ [6]. Then, the solubility parameter calculation of the naphthenic oil is quite straightforward according to

$$
(0.45 \times 16.8)+(0.35 \times 12.8)+(0.2 \times 18.5)=15.7 \mathrm{MPa}^{1 / 2} \text {. }
$$

(c) Aromatic Oil. It is essentially made a "core" of two condensed benzene rings (naphthalene) which are well represented indeed by naphthalene whose solubility parameter is 20.2 $\mathrm{MPa}^{1 / 2}$ [6], representing about $50 \%$ of the total carbon content. The naphthenic part of the oil can be represented by the cyclohexane molecule which has a $\delta_{t}=16.8 \mathrm{MPa}^{1 / 2}$ [6], and the naphthenic molecules may represent $20 \%$ of the total carbon atoms. The paraffinic part of the molecule represents about $30 \%$ of the total carbon atoms which may be best represented by neopentane which has a solubility parameter of $12.8 \mathrm{MPa}^{1 / 2}$ [2]. Then, the solubility parameter calculation of the aromatic oil is quite straightforward according to

$$
(0.5 \times 20.2)+(0.2 \times 16.8)+(0.3 \times 12.8)=17.3 \mathrm{MPa}^{1 / 2} .
$$

3.4. Evaluation of the Solubility of Rubbers in Selected Plasticizers. There are numerous ways of evaluation of the solubility of a given polymer $P$ in a given solvent $S$; Van Krevelen [21] suggests the criteria imposed by the following:

$$
\Delta \delta=\left[\left(\delta_{d, P}-\delta_{d, S}\right)^{2}+\left(\delta_{p, P}-\delta_{p, S}\right)^{2}+\left(\delta_{h, P}-\delta_{h, S}\right)^{2}\right]^{0.5} .
$$

To predict solubility

$$
\Delta \delta \leq 5
$$

Alternatively, Hansen [6] has proposed a more sophisticated and relatively complex approach for the evaluation of the solubility of a polymer in a solvent. The problem in the present study regards the fact that, for all the solutes and solvents considered here, we have available the total solubility 
parameter $\delta_{t}$, but in most cases we do not have available the separate contributions to $\delta_{t}$ in terms of $\delta_{d}, \delta_{p}$, and $\delta_{h}$. Therefore, we have preferred to adopt the simplest possible approach in the evaluation of the solubility between a polymer and a solvent which conform to the criteria imposed by the following:

$$
|\Delta \delta|=\left(\delta_{t, P}-\delta_{t, S}\right),
$$

a criteria proposed by Brydson [2].

Table 3 shows a summary of these calculations made according to (17). At the bottom of Table 3 are reported the $|\Delta \delta|$ values of a series of methyl esters of fatty acids and a series of rubbers. From the data reported, it is evident that we must expect an excellent solubility of EPDM, butyl rubber, polyisoprene (natural rubber), polybutadiene, and SBR (styrene-butadiene copolymers) in all methyl esters of fatty acids and consequently also in biodiesel which is just a mixture of different types of methyl esters of fatty acids. The reason of this expected solubility is derived from the extremely low value in line with the disequation $\left|\Delta \delta_{t}\right|<$ 1. Indeed, our experiments on dissolution of polyisoprene, polybutadiene, and SBR-20 in biodiesel were completely successful. Thus, the theoretical expectation of the solubility of diene rubbers in biodiesel has found a clear experimental confirmation. In this context, the solubility parameter of biodiesel $\delta_{t}=17.6 \mathrm{MPa}^{1 / 2}$ reported by other authors [7] appears, after all, reasonably close to the value calculated by us for biodiesel $\delta_{t}=16.6 \mathrm{MPa}^{1 / 2}$. In view of the experimental results which have confirmed the easy solubility of diene rubbers in biodiesel, $16.6 \mathrm{MPa}^{1 / 2}$ should be taken as the reference value for the biodiesel solubility parameter. Looking at Table 2, it is also possible to expect less solubility by polystyrene and by nitrile rubber in biodiesel. A specific experiment of dissolution of polystyrene in biodiesel has revealed that it is soluble, but the approximate concentration reached is $2 \mathrm{mg} / \mathrm{mL}$, while in the case of polyisoprene, polybutadiene, and SBR, we were able to reach concentrations as high as $10 \mathrm{mg} / \mathrm{mL}$, and probably it was possible to go above that value without problems.

Table 3 shows also that the triglycerides of fatty acids have a solubility parameter very close to that of biodiesel and the methyl esters of fatty acids. This fact is not surprising; it is in line with expectation, and hence, based on the data of Table 3 , it is possible to affirm that fatty acids esters either methyl esters or under the form of glycerides are good plasticizers of diene rubbers and in particular of EPDM, butyl rubber, polyisoprene, polybutadiene, and SBR. A slight different behavior in terms of solubility is expected for castor oil which is characterized by a unique chemical structure among the fatty acids triglycerides, since it contains also hydroxyl groups due to ricinoleic acid. This fact explains the relatively high solubility parameter of castor oil in comparison to the other vegetable oils [3].

Table 3 shows also the solubility parameters and the $\left|\Delta \delta_{t}\right|$ values with a series of rubbers of the conventional plasticizers prepared from oil which were discussed in Section 3.3. Based on the $\left|\Delta \delta_{t}\right|$ values, paraffinic oil is suitable essentially for EPDM and for butyl rubber. It is still acceptable also for the other rubbers reported in Table 3, but its compatibility drops gradually from polyisoprene to polystyrene and nitrile as intuitively expected. Naphthenic oil is instead a very good solvent for EPDM, butyl, and polyisoprene, but with BR and SBR, its compatibility gradually decreases. Aromatic oil is instead very compatible with SBR and still acceptable also for natural rubber and polyisoprene. Also, the last case is completely in line with the experience.

Less common plasticizers reported in Table 3 are the adipate, sebacate, and phthalate esters. These esters (and other similar) are used especially in the formulation of winter tire treads. As expected the most aliphatic esters adipate and sebacate have a wider compatibility with all rubbers while the most aromatic esters based on phthalates appear more compatible with SBR, polystyrene, and nitrile rubber.

In conclusion, the simplest approach of using the $\left|\Delta \delta_{t}\right|$ appears useful and completely in line with the experience. $\left|\Delta \delta_{t}\right|$ can be viewed as a quantitative estimation of a given rubber solubility into a given plasticizer. In Table 3 , we have used four color codes as a guidance of the solubility between the polymers in the plasticizer. The bold font indicates the best solubility followed by the italic font and the bold italic font code. The underline font suggests already a certain lack of compatibility to a certain extent.

\subsection{Solubility Parameter and Behavior of a Plasticizer in} a Rubber Matrix. There is other useful information which can be extracted from the solubility parameters and regard the behavior of a plasticizer in a rubber matrix. In fact, it is possible to distinguish between plasticizers which act as internal lubricants from plasticizers which instead act as external lubricants. Internal lubricants are those plasticizer molecules which facilitate the movements of a polymer chain segment with regard to an adjacent polymer segment. External lubricants are instead low compatibility plasticizers which tend to migrate on the surface of the rubber matrix and they act as a processing aid, for example, in the extrusion process or in conferring tackiness to the rubber surface. Ideally, internal lubricants must have a high compatibility with a rubber matrix, that is, $\left|\Delta \delta_{t}\right| \rightarrow 0$, and instead an external lubricant is characterized by higher values of $\left|\Delta \delta_{t}\right|$.

Let us read the data in Table 3 under other optics: let us change (17) into the following:

$$
\Delta \delta=\left(\delta_{t, P}-\delta_{t, S}\right) .
$$

In other words, let us now consider the sign of the interaction. The simplest case is that $\delta_{t, P} \approx \delta_{t, S}$, and this condition corresponds again to the fact that the plasticizer and polymer are mutually soluble, and hence, the plasticizer acts also as an internal lubricant.

The condition when $\left|\Delta \delta_{t}\right| \gg 0$ means that we are dealing with an external lubricant and can be resolved into two cases. If $\delta_{t, P}>\delta_{t, S}$ then $\Delta \delta>0$, and, of course, if $\delta_{t, P}<\delta_{t, S}$ then $\Delta \delta<0$. In the first case, when the solubility parameter of the plasticizer is higher than that of the polymer, the sign is positive and the plasticizer acts as an external lubricant effective on the surface of the filler. The higher polarity and/or aromaticity of the plasticizer implies that the plasticizer 
TABLE 3: Difference $\left|\Delta \delta_{t}\right|$ between the solubility parameter of the plasticizer and the solubility parameter of the rubber.

\begin{tabular}{|c|c|c|c|c|c|c|c|c|c|}
\hline & $\begin{array}{c}\delta_{t} \text { in } \\
\mathrm{MPa}^{1 / 2}\end{array}$ & $\begin{array}{c}\left|\Delta \delta_{t}\right| \\
\text { EPDM and IIR }\end{array}$ & $\begin{array}{c}\left|\Delta \delta_{t}\right| \\
\mathrm{NR} \\
\end{array}$ & $\begin{array}{c}\left|\Delta \delta_{t}\right| \\
\mathrm{BR} \\
\end{array}$ & $\begin{array}{c}\left|\Delta \delta_{t}\right| \\
\text { SBR-20 }\end{array}$ & $\begin{array}{c}\left|\Delta \delta_{t}\right| \\
\text { SBR-40 }\end{array}$ & $\begin{array}{c}\left|\Delta \delta_{t}\right| \\
\text { PS }\end{array}$ & $\begin{array}{c}\left|\Delta \delta_{t}\right| \\
\text { NITRILE-20 }\end{array}$ & $\begin{array}{c}\left|\Delta \delta_{t}\right| \\
\text { NITRILE-30 } \\
\end{array}$ \\
\hline Paraffinic oil (this work) & 14.2 & -1.9 & -2.3 & -2.9 & -3.2 & -3.5 & -4.5 & -5.2 & -6.4 \\
\hline Naphthenic oil (this work) & 15.7 & -0.4 & -0.8 & -1.4 & -1.7 & -2.0 & $\underline{-3.0}$ & -3.7 & $\underline{-4.9}$ \\
\hline Aromatic oil (this work) & 17.3 & 1.2 & 0.8 & 0.2 & -0.1 & -0.4 & -1.4 & -2.1 & $\underline{-3.3}$ \\
\hline Diisooctyl adipate [2] & 17.8 & 1.7 & 1.3 & 0.7 & 0.4 & 0.1 & -0.9 & -1.6 & -2.8 \\
\hline Dioctyl sebacate [2] & 17.8 & 1.7 & 1.3 & 0.7 & 0.4 & 0.1 & -0.9 & -1.6 & -2.8 \\
\hline Diethylhexyl phthalate [2] & 18.2 & 2.1 & 1.7 & 1.1 & 0.8 & 0.5 & -0.5 & -1.2 & -2.4 \\
\hline Dioctyl phthalate [6] & 18.3 & 2.2 & 1.8 & 1.2 & 0.9 & 0.6 & -0.4 & -1.1 & -2.3 \\
\hline Diethylhexyl phthalate [6] & 19.0 & 2.9 & 2.5 & 1.9 & 1.6 & 1.3 & 0.3 & -0.4 & -1.6 \\
\hline Dibutyl phthalate [2] & 19.2 & $\underline{3.1}$ & 2.7 & 2.1 & 1.8 & 1.5 & 0.5 & -0.2 & -1.4 \\
\hline Olive oil [3] & 16.9 & 0.8 & 0.4 & -0.2 & -0.5 & -0.8 & -1.8 & -2.5 & -3.7 \\
\hline Soybean oil [3] & 16.2 & 0.1 & -0.3 & -0.9 & -1.2 & -1.5 & -2.5 & -3.2 & $\underline{-4.4}$ \\
\hline Sunflower oil [3] & 16.7 & 0.6 & 0.2 & -0.4 & -0.7 & -1.0 & -2.0 & -2.7 & -3.9 \\
\hline Peanut oil [3] & 16.1 & 0.0 & -0.4 & -1.0 & -1.3 & -1.6 & -2.6 & $\underline{-3.3}$ & $\underline{-4.5}$ \\
\hline Lineseed oil [3] & 16.4 & 0.3 & -0.1 & -0.7 & -1.0 & -1.3 & -2.3 & -3.0 & -4.2 \\
\hline Brassica oil [3] & 16.9 & 0.8 & 0.4 & -0.2 & -0.5 & -0.8 & -1.8 & -2.5 & $\underline{-3.7}$ \\
\hline Castor oil [3] $]^{*}$ & 18.3 & 2.2 & 1.8 & 1.2 & 0.9 & 0.6 & -0.4 & -1.1 & -2.3 \\
\hline Methyl erucate (this work) & 16.6 & 0.5 & 0.1 & -0.5 & -0.8 & -1.1 & -2.1 & -2.8 & -4.0 \\
\hline Methyl oleate (this work) & 16.7 & 0.6 & 0.2 & -0.4 & -0.7 & -1.0 & -2.0 & -2.7 & -3.9 \\
\hline Methyl linoleate (this work) & 16.6 & 0.5 & 0.1 & -0.5 & -0.8 & -1.1 & -2.1 & -2.8 & $\underline{-4.0}$ \\
\hline Methyl stearate (this work) & 16.7 & 0.6 & 0.2 & -0.4 & -0.7 & -1.0 & -2.0 & -2.7 & -3.9 \\
\hline Methyl palmitate (this work) & 16.6 & 0.5 & 0.1 & -0.5 & -0.8 & -1.1 & -2.1 & -2.8 & $\underline{-4.0}$ \\
\hline Biodiesel (this work) & 16.6 & 0.5 & 0.1 & -0.5 & -0.8 & -1.1 & -2.1 & -2.8 & -4.0 \\
\hline Biodiesel [7] & 17.6 & 1.5 & 1.1 & 0.5 & 0.2 & -0.1 & -1.1 & -1.8 & $\underline{-3.0}$ \\
\hline
\end{tabular}

*Hansen reports a value of $20.4 \mathrm{MPa}^{1 / 2}$

EPDM: ethylene/propylene/diene rubber; IIR: butyl rubber; NR: natural rubber (polyisoprene); BR: polybutadiene; SBR-20: styrene/butadiene copolymer 20\% styrene; SBR-40: styrene/butadiene copolymer 40\% styrene; PS: polystyrene; NITRILE-20: acrylonitrile/butadiene copolymer 20\% acrylonitrile; NITRILE-30: acrylonitrile/butadiene copolymer $30 \%$ acrylonitrile.

Bold font : $\left|\Delta \delta_{t}\right|<1$.

Italic font : $1.0<\left|\Delta \delta_{t}\right|<1.9$.

Bold italic font : $1.9<\left|\Delta \delta_{t}\right|<2.9$.

Underline font : $\left|\Delta \delta_{t}\right|>3$.

becomes preferentially adsorbed on the filler surface to which it has higher affinity forming a layer between polymer and filler enhancing the processability which can be viewed in terms of a facilitation of filler incorporation and dispersion inside the polymer matrix. The plasticizer by forming a film on the surface of the filler reduces the surface energy of the filler itself and consequently facilitates the polymerfiller interaction [6]. The estimated solubility parameters of some fillers are worth mentioning here: carbon black $\delta_{t}=22-33 \mathrm{MPa}^{1 / 2}$ and silicate fillers $\delta_{t}=30-40 \mathrm{MPa}^{1 / 2}$. Furthermore in the condition of $\delta_{t, P}>\delta_{t, S}$, then $\Delta \delta>0$; the plasticizer may act as a tackifier on the surface of the rubber compound but the tackifier behavior is also affected by other properties of the plasticizer like its softening or melting point and the working temperature range where one is operating. The opposite conditions $\delta_{t, P}<\delta_{t, S}$ then $\Delta \delta<0$ imply instead that the polymer is more polar or aromatic than the plasticizer; these are considered the most desirable conditions to have a plasticizer which acts as a simple external lubricant of the rubber compound as a flow improver, for example, in the extrusion process. Also in this case, the exudation of the plasticizer is possible especially if the polymer matrix is highly polar in comparison to the modest polarity of the plasticizer. Plasticizer bleeding is a risk is designed with a large amount of plasticizer.

3.6. Biodiesel Behavior in a Rubber Compound. Based on the data of Table 3, biodiesel acts as an internal lubricant with apolar rubbers like EPDM, butyl rubber, polyisoprene, polybutadiene, and SBR at moderate amount of styrene. In the case of high styrene SBR ( $>40 \%)$, the biodiesel starts to work also as an external lubricant, and being $\Delta \delta<0$, it is evident that in this case the biodiesel will concentrate on the external surface of the rubber compound.

There are little differences in the plasticizing effects of biodiesel in comparison for instance with an aromatic mineral oil. The latter shows also high compatibility with all the common rubber shown in Table 3 with some exception with EPDM and butyl rubber. Thus, also an aromatic mineral oil (like for instance a T-RAE = Treated Residual Aromatic Extract) acts as an internal lubricant with polyisoprene, polybutadiene, and SBR, and only with polystyrene and 
TABLE 4: Cure kinetics and scorch.

\begin{tabular}{lcc}
\hline Rheometer test at $160^{\circ} \mathrm{C}$ & Reference & Biodiesel \\
\hline $\mathrm{ML}(\mathrm{dNm})$ & 3.07 & 3.13 \\
$\mathrm{MH}(\mathrm{dNm})$ & 15.04 & 13.24 \\
$\mathrm{MH}-\mathrm{ML}(\mathrm{dNm})$ & 12.0 & 10.1 \\
$\mathrm{~T} 10(\mathrm{~min})$ & 3.34 & 3.25 \\
$\mathrm{~T} 50(\mathrm{~min})$ & 5.07 & 4.50 \\
$\mathrm{~T} 90(\mathrm{~min})$ & 8.19 & 7.34 \\
Mooney scorch $(\mathrm{min}) 127^{\circ} \mathrm{C}$ & 19.00 & 17.26 \\
Mooney viscosity $100^{\circ} \mathrm{C}$ & 52 & 49 \\
\hline
\end{tabular}

nitrile rubber, it starts to work as an external lubricant with possible blooming on the surfaces of these polymer matrices. Conversely, the aromatic mineral oil could partly act as an activator of filler surface when used with EPDM and butyl rubber.

\subsection{Experimental Behavior of Biodiesel in a Passenger Tread} Compound in Comparison to a Mineral Aromatic Oil. Rubber compounds with SBR are commonly compounded with aromatic mineral oil of the type of T-RAE. In this study we have replaced the free mineral oil of a standard rubber compound intended for tread application with a commercial biodiesel. As reported in the experimental section, in an SBRbased rubber compound $20 \mathrm{phr}$ of free oil was substituted with $20 \mathrm{phr}$ of biodiesel. Table 4 shows the results of such a change in terms of rheometrical properties (a measurement of the cure kinetics and crosslinking density made at $160^{\circ} \mathrm{C}$ ), Mooney scorch time (a measurement of the tendency to premature vulcanization made at $127^{\circ} \mathrm{C}$ ), and Mooney viscosity (a measurement of the viscosity of the compounds expressed in Mooney scale and made at $100^{\circ} \mathrm{C}$ ).

The rheometrical data show that biodiesel reduces the maximum torque $(\mathrm{MH})$, and consequently, it reduces also the crosslinking density of the compound as shown by the lower value ( $12 \%$ less) of the MH-ML in comparison to that of the reference compound. This result is derived from the fact that biodiesel is a reactive plasticizer sensitive to the sulphur-based vulcanization because the methyl esters of fatty acids composing the biodiesel are unsaturated. For example, biodiesel produced from rapeseed oil has an iodine number (a measurement of the unsaturation) of $110 \mathrm{~g} / 100 \mathrm{~g}$ and reaches the value of $130-135 \mathrm{~g} / 100 \mathrm{~g}$ when the biodiesel is derived from soybean and sunflower. The biodiesel used by us was of rapeseed origins. The mechanism which leads to a reduction of the crosslinking density implies that part of the available sulphur is lost in crosslinks between the plasticizer and the rubber chains and between plasticizer molecules, while in the reference compound all the available sulphur is used in the crosslinking reactions between the polymer chains, being sulphur not reactive with aromatic oil. Another aspect which can be observed from the data in Table 4 regards the fact that biodiesel accelerates cure kinetics in comparison to reference, and this fact is observed also in a reduced Mooney scorch time in comparison to reference compound. Furthermore, in Table 4, it is possible to
TABLE 5: Cured physical properties.

\begin{tabular}{lcc}
\hline & Reference & Biodiesel \\
\hline Tensile strength $(\mathrm{MPa})$ & 18.7 & 16.9 \\
Modulus at $50 \%(\mathrm{MPa})$ & 1.06 & 0.88 \\
Modulus at $100 \%(\mathrm{MPa})$ & 1.69 & 1.29 \\
Modulus at $200 \%(\mathrm{MPa})$ & 4.29 & 2.90 \\
Modulus at $300 \%(\mathrm{MPa})$ & 8.26 & 5.61 \\
Modulus at $400 \%(\mathrm{MPa})$ & 12.28 & 8.70 \\
Modulus at 500\% $(\mathrm{MPa})$ & 16.03 & 11.73 \\
Elongation at break $\%$ & 580 & 687 \\
Hardness shore A & 69 & 64 \\
Hardness shore A at $100^{\circ} \mathrm{C}$ & 57 & 54 \\
\hline
\end{tabular}

observe a reduced Mooney viscosity (3 Mooney points lower) of the compound prepared with biodiesel in comparison to the reference rubber compound with mineral oil. This effect on viscosity can be simply explained by the fact that the viscosity of pure biodiesel is considerably lower than that of an aromatic oil plasticizer of the type of T-RAE. The lower viscosity of biodiesel is also manifested in the relative rubber compound. In general, a lower viscosity is judged positively because it improves the rubber compound processability, for example, it gives a better extrudability.

In Table 5, the physical properties of the cured rubber compounds are reported. As already anticipated from the rheometrical properties and from the lower crosslinking density of the compound plasticized with biodiesel, in Table 5, A lower tensile strength and systematically lower modulus for such a compound in comparison to the reference can be observed. The reduction of tensile strength in the biodieselbased compound is about $-10 \%$ in comparison to reference, and it is compensated by a higher elongation at break $(+18 \%)$ for the biodiesel-based compound which is again due to the lower crosslinking density of this compound. The modulus measured at lower and high extension in the biodieselbased compound is systematically lower than the reference compound, and the effect is more pronounced at higher elongations. As expected also the hardness of the biodieselbased compound is lower than the reference. After all, the hardness is a measure of modulus under compression rather than extension and at low displacements, and in fact, the differences in comparison to the reference are limited to $-6 \%$ or $-7 \%$.

The viscoelastic properties of a cured rubber compound are measured at the mechanical spectrometer. Two components are the key parameter of the viscoelastic behavior: the elastic modulus $G^{\prime}$ which is known also as storage modulus and the viscous modulus $G^{\prime \prime}$ which is known also as loss modulus [21]. The two parameters were measured in our case at $1 \%$ extension and at a frequency of $80 \mathrm{~Hz}$. The ratio between the viscous modulus and the elastic modulus is known as $\tan \delta$ :

$$
\tan \delta=\frac{G^{\prime \prime}}{G^{\prime}} .
$$


TABLE 6: Dynamic properties at the mechanical spectrometer.

\begin{tabular}{lcc}
\hline & Reference & Biodiesel \\
\hline Elastic modulus $G^{\prime}$ at $-20^{\circ} \mathrm{C}$ & 206.3 & 105.0 \\
Tan $\delta$ & 0.438 & 0.231 \\
\hline Elastic modulus $G^{\prime}$ at $0^{\circ} \mathrm{C}$ & 81.3 & 55.8 \\
Tan $\delta$ & 0.190 & 0.165 \\
\hline Elastic modulus $G^{\prime}$ at $+30^{\circ} \mathrm{C}$ & 36.5 & 27.9 \\
Tan $\delta$ & 0.177 & 0.165 \\
\hline Elastic modulus $G^{\prime}$ at $+70^{\circ} \mathrm{C}$ & 22.4 & 17.3 \\
Tan $\delta$ & 0.169 & 0.166 \\
\hline
\end{tabular}

In Table 6 , the $G^{\prime}$ and $\tan \delta$ values measured on the reference and on the biodiesel-based compound under different temperature conditions are reported. It is evident that the dynamic behavior of the two compounds is quite different. As usual, the biodiesel-based compound is affected by a low $G^{\prime}$ which is a consequence of the general lower crosslinking density. However, low $G^{\prime}$ at low and very low temperatures is judged positively for a winter tread because the low values of the elastic modulus imply more grip even under extreme conditions of traction on snow or ice [23,24]. Conversely, the dry traction is "read" on the $G^{\prime}$ value at $30^{\circ} \mathrm{C}$ and especially on $\tan \delta$ at $30^{\circ} \mathrm{C}$. The latter value is not far from that of the reference for the biodiesel-compounded sample. Similarly, the rolling resistance is suggested by the tan $\delta$ value at $70^{\circ} \mathrm{C}$, and the value measured on the biodiesel-based compound is in this case almost identical to that of the reference compound $[23,24]$. Concerning wet traction, a predictor is the $\tan \delta$ at $0^{\circ} \mathrm{C}$, and in this case, the biodiesel-based compound is $13 \%$ lower in performance against the reference compound $[23,24]$.

\section{Conclusions}

The work is divided into two parts. In the first part, the solubility parameter of the methyl esters of fatty acids was calculated according to the Van Krevelen procedure $[3,21]$. The solubility parameter of biodiesel was then obtained and compared with that of a series of rubbers and mineral oil aromatic, naphthenic, and paraffinic. From the calculation a good solubility of EPDM, butyl rubber, polyisoprene (natural rubber), polybutadiene, and SBR (low styrene) in biodiesel was expected. The theoretical expectation based on the evaluation of the solubility parameter has found a clear experimental confirmation as reported in the experimental Section 2.3. Further reflections on the solubility parameter of biodiesel has led to the conclusion that this plasticizer not only is fully compatible with diene rubber but also acts essentially as an internal lubricant in a rubber compound.

The experimental study has shown that the biodieselbased compound gives a different behavior in a cured rubber matrix. First of all, the methyl esters of fatty acids are definitely reactive with the sulphur used in the curing process and subtract part of the available sulphur to the crosslinking process of the rubber chains leading to lower modulus, lower tensile, and higher elongation. The low modulus is beneficial for the low temperature behavior of the biodieselbased rubber compound which shows potential application in winter (snow and ice) passenger tire tread formulations without detrimental effects in the dry traction and rolling resistance. Some potential weakness of the biodiesel-based rubber compound could occur in the wet traction. However, the present study is only an exploratory study aimed to demonstrate the potentiality of biodiesel as an alternative plasticizer from renewable sources against the mineral oil derived plasticizers. Further work is certainly needed to optimize the behavior of the biodiesel. For example, it should be part of the fine tuning work the necessity to increase the modulus of the biodiesel-based rubber compound and this can be achieved by increasing the sulphur content of the formulation. It is expected that a correct increase in the sulphur content will be beneficial in increasing the moduli and the tensile to the same level of the reference compound, but the interesting potential application in winter tire tread will remain evident even after the fine tuning adjustments.

\section{References}

[1] W. A. Schneider, F. Huybrechts, and K. H. Nordsiek, "Process oils in oil extended SBR," Katschuk Und Gummi Kuststoffe, vol. 44, pp. 528-536, 1991.

[2] J. A. Brydson, Rubber Chemistry, Applied Science, London, UK, 1978.

[3] F. Cataldo, "Solubility of fullerenes in fatty acids esters: a new way to deliver in vivo fullerenes. Theoretical calculations and experimental results," in Medicinal Chemistry and Pharmacological Potential of Fullerenes and Carbon Nanotubes, F. Cataldo and T. Da Ros, Eds., chapter 13, Springer Science, Dordrecht, The Netherlands, 2008.

[4] C. D. Vaughan, "Using solubility parameters in cosmetics formulation," Journal of the Society of Cosmetic Chemists of Japan, vol. 36, no. 5, pp. 319-333, 1985.

[5] S. Saka and D. Kusdiana, "Biodiesel fuel from rapeseed oil as prepared in supercritical methanol," Fuel, vol. 80, no. 2, pp. 225231, 2001.

[6] C. M. Hansen, Hansen Solubility Parameters: A User's Handbook, CRC Press/Taylor \& Francis, Boca Raton, Fla, USA, 2007.

[7] Y. Zhang, S. K. Mallapragada, and B. Narasimhan, "Dissolution of waste plastics in biodiesel," Polymer Engineering and Science, vol. 50, no. 5, pp. 863-870, 2010.

[8] D. Kimber and D. I. McGregor, Brassica Oilseeds: Production and Utilization, CAB International, Wallingford, UK, 1995.

[9] H. Niewiadomski, Rapeseed Chemistry and Technology, Elsevier, Amsterdam, The Netherlands, 1990.

[10] B. R. Moser, "Biodiesel production, properties, and feedstocks," In Vitro Cellular and Developmental Biology-Plant, vol. 45, no. 3, pp. 229-266, 2009.

[11] L. Tao and A. Aden, "The economics of current and future biofuels," In Vitro Cellular and Developmental Biology-Plant, vol. 45, no. 3, pp. 199-217, 2009.

[12] A. Karmakar, S. Karmakar, and S. Mukherjee, "Properties of various plants and animals feedstocks for biodiesel production," Bioresource Technology, vol. 101, no. 19, pp. 7201-7210, 2010. 
[13] H. J. Nieschlag and I. A. Wolff, "Industrial uses of high erucic oils," Journal of the American Oil Chemists Society, vol. 48, pp. 723-727, 1971.

[14] T. W. Wilson, "Rubber composition with non-petroleum oils," US Patent 7,211,611 B2, 2007.

[15] C. M. Flanigan and C. Perry, "Rubber composition containing oil blend of petroleum oil and a biobased and methods of making the same," US Patent 8,034,859 B2, 2011.

[16] J. Wehlmann, "Use of esterified rapeseed oil as plasticizer in plastics processing," European Journal of Lipid Science and Technology, vol. 101, pp. 249-256, 1999.

[17] V. Nandanan, R. Joseph, and K. E. George, "Rubber seed oil: a multipurpose additive in NR and SBR compounds," Journal of Applied Polymer Science, vol. 72, no. 4, pp. 487-492, 1999.

[18] P. P. Kundu, "Improvement of filler-rubber interaction by the coupling action of vegetable oil in carbon black reinforced rubber," Journal of Applied Polymer Science, vol. 75, pp. 735-739, 2000.

[19] S. Salehpour and M. A. Dubé, "Biodiesel: a green polymerization solvent," Green Chemistry, vol. 10, pp. 321-326, 2008.

[20] J. Bicerano, Prediction of Polymer Properties, Marcel Dekker, New York, NY, USA, 2nd edition, 1996.

[21] D. W. Van Krevelen, Properties of Polymers. Their Correlation with Chemical Structure, Their Numerical Estimation and Prediction from Additive Group Contributions, Elsevier, Amsterdam, The Netherlands, 3rd edition, 1990.

[22] G. B. Martinenghi, TEcnologia Chimica Industriaie Degli Oli Grassi e Derivati, Ulrico Hoepli, Milan, Italy, 3rd edition, 1963.

[23] S. Futamura, "Effect of material properties on tire performance characteristics. Part II, tread material," Tire Science and Technology, vol. 18, no. 1, pp. 2-12, 1990.

[24] S. Futamura, "Analysis of ice- and snow traction of tread material," Rubber Chemistry and Technology, vol. 69, no. 4, pp. 648-653, 1996. 

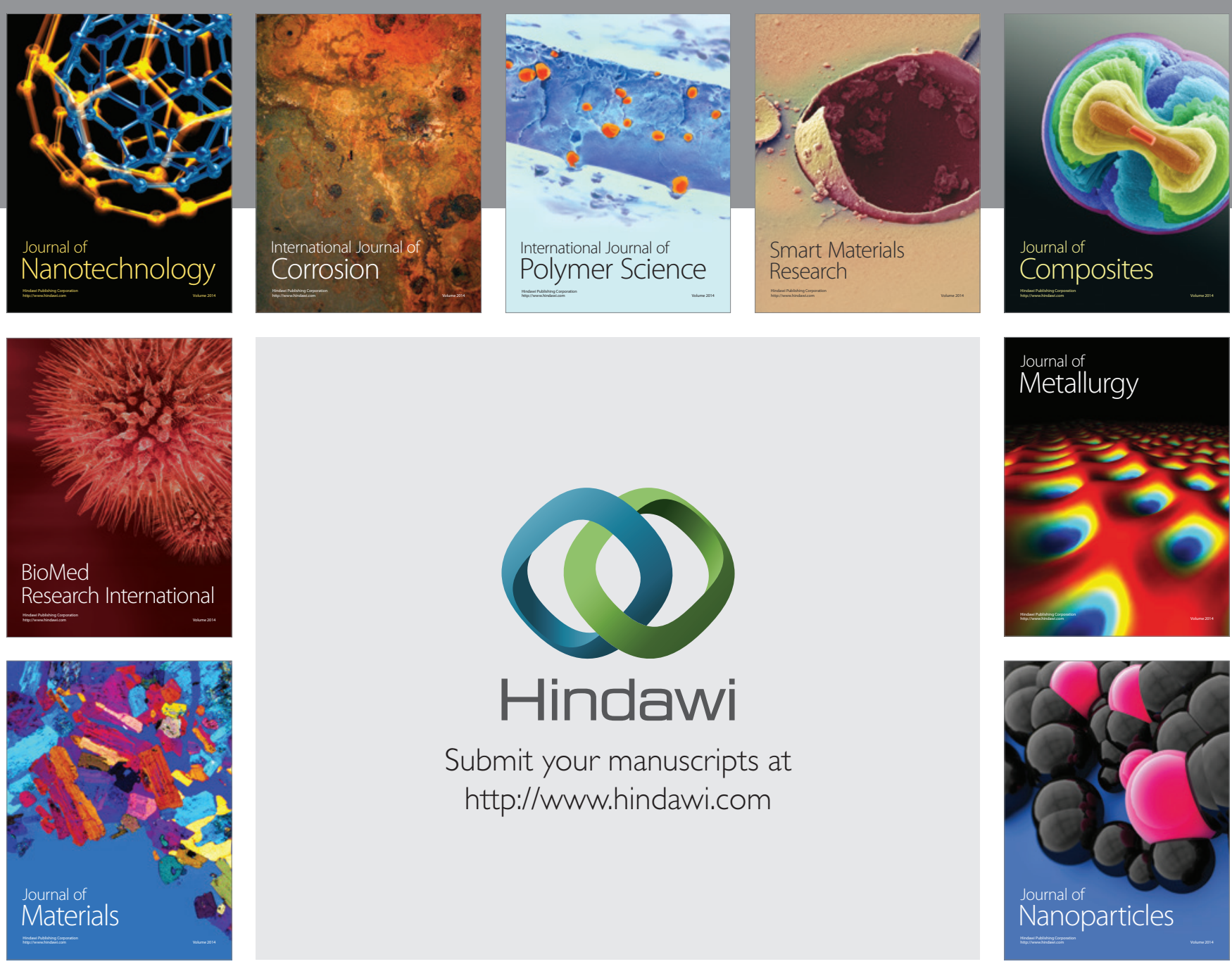

Submit your manuscripts at http://www.hindawi.com
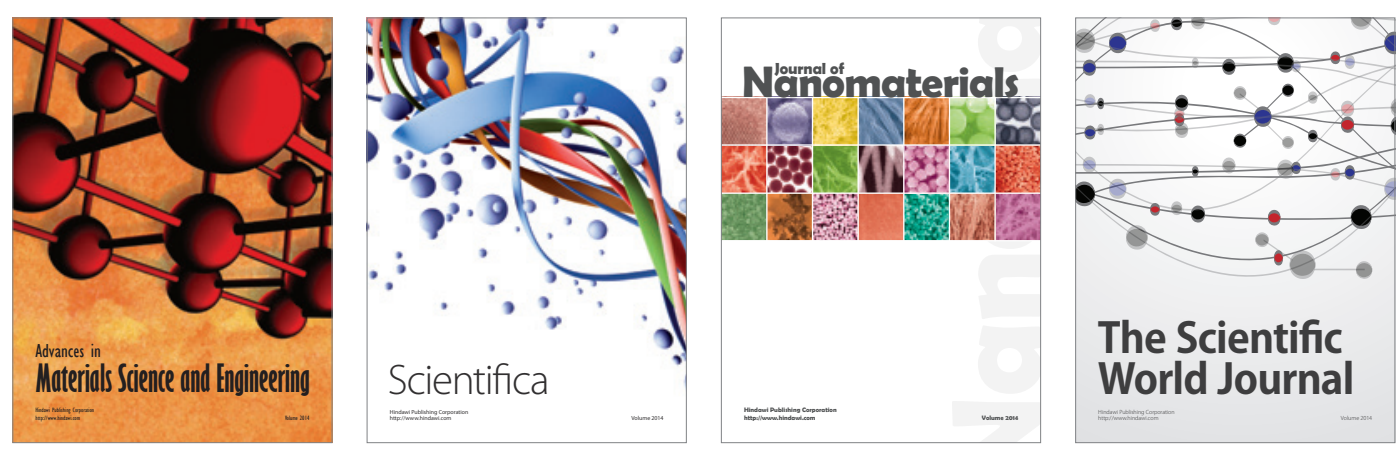

\section{The Scientific World Journal}
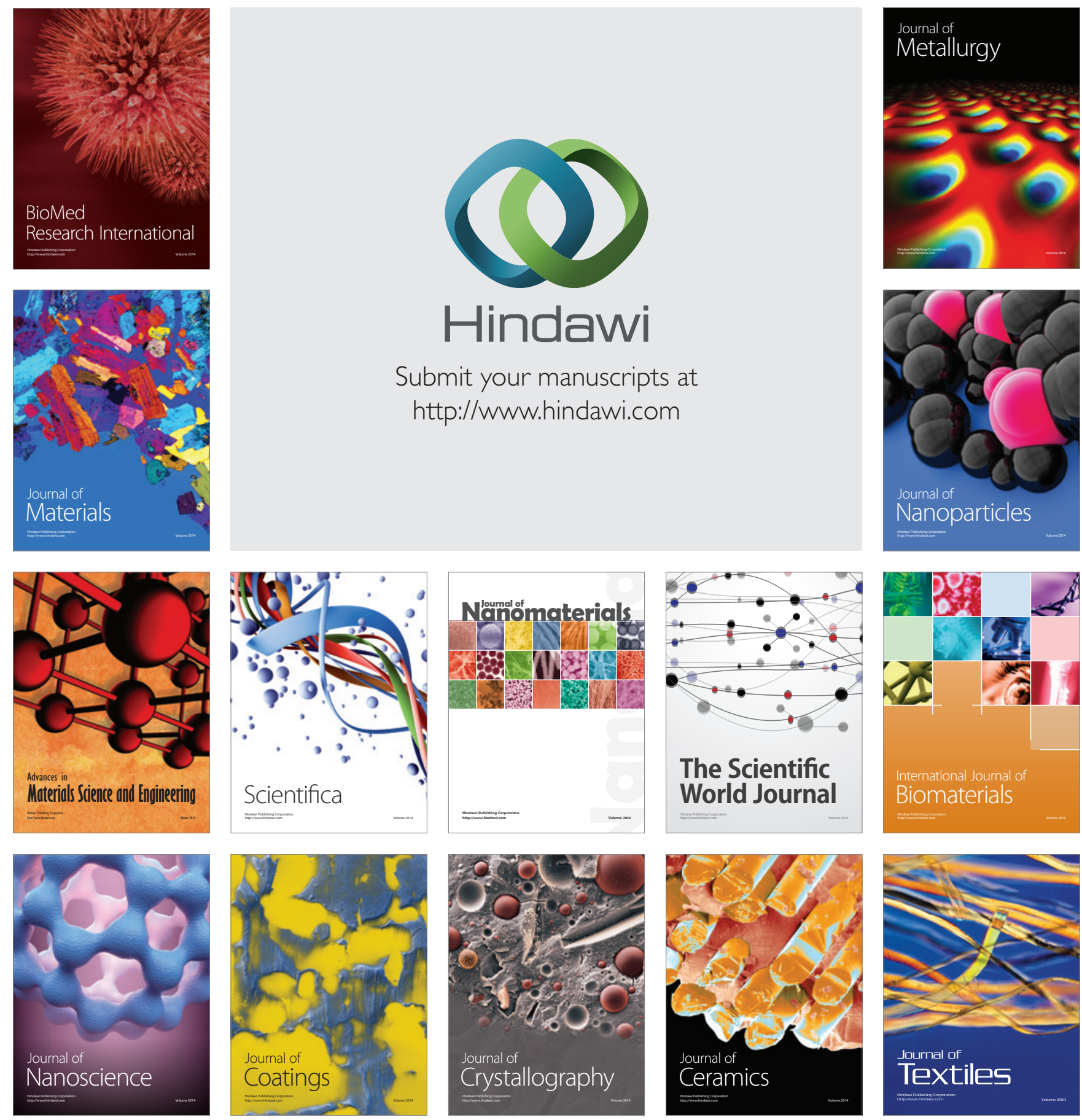